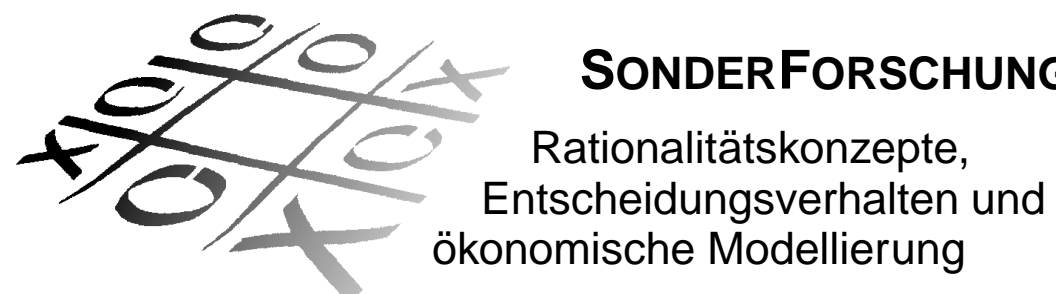

No. $02-05$

The German UMTS Design: Insights From Multi-Object Auction Theory

\author{
Moldovanu, Benny* \\ and Ewerhart, Christian**
}

December 2001

C. Ewerhart thanks Mathias Meisel, portfolio manager at Zurich Invest, for many insightful discussions concerning the telecommunications industry. B. Moldovanu wishes to acknowledge the long cooperation with Philippe Jehiel. This cooperation has shaped several main ideas in this paper. We also wish to thank the participants at the CES/IFO conference on auctions and telecommunications for their many helpful comments.

*Department of Economics, University of Mannheim, Germany, email: mold@pool.uni-mannheim.de

**Sonderforschungsbereich 504, email: ewerhart@sfb504.uni-mannheim.de

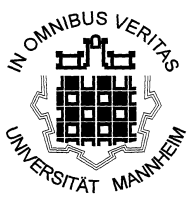

Universität Mannheim

$L 13,15$

68131 Mannheim 


\title{
The German UMTS Design: Insights From Multi-Object Auction Theory
}

\author{
Christian Ewerhart and Benny Moldovanu*
}

5.12 .2001

\begin{abstract}
We briefly survey several insights about value and revenue maximization in multi-object auctions and apply them to the German (and Austrian) UMTS auction. In particular, we discuss in detail the exposure probelm that caused firms in Germany to pay almost Euro 20 billion for nothing.
\end{abstract}

\section{The Main Aspects of License Auction Design}

The recent European 3G license auctions focused the public attention and the debate among practitioners and academic economists on several issues pertaining to multi-object auctions. In fact, the most important issues in the design of license auctions are placed at the intersection of industrial organization and mechanism design (see the papers listed in Jehiel and Moldovanu, 2000a) The point is that license auctions or (other procedures such as beauty contests) do not only allocate scarce goods, but also determine the nature of whole industries where entry is otherwise almost impossible. Hence the outcome of any allocation procedure influences the future interaction among winning firms, regulator (i.e., government) and consumers. This obvious effect should be taken in account for applications of auction theory to license auctions (it is interesting to note that many financial and telecom analysts explicitly took this effect in consideration in their reports ${ }^{1}$ )

Because of the market structure effects, valuations (which depend on expectations about future market structure) are determined by the allocation procedure itself, and are therefore endogenous. This creates another twist: potential acquirers of licenses will anticipate the future scenarios as a function of the auction's

${ }^{*}$ C. Ewerhart thanks Mathias Meisel, portfolio manager at Zurich Invest, for many insightful discussions concerning the telecommunications industry. B. Moldovanu wishes to acknowledge the long cooperation with Philippe Jehiel. This cooperation has shaped several main ideas in this paper. We also wish to thank the participants at the CES/IFO conference on auctions and telecommunications for their many helpful comments.

${ }^{1}$ For example, a major investment bank, estimated per license values of Euro 14.75 Bn, 15.88 Bn and 17.6 Bn for a German symmetric market with 6, 5, or 4 firms, respectively. 
outcome, and they will condition their behavior before and during the auction on those expectations. Failing to take into account these basic strategic motives at the design stage can have harsh consequences for governments and/or consumers.

\subsection{Efficiency versus Value Maximization}

Given the above observation, a maxim such as "Put the licenses in the hands of those who value them most" is nonsense in the context of European $3 \mathrm{G}$ auctions since the main goal of most license auction is economic efficiency. But economic efficiency means that some weighted sum of firms values and consumer surplus should be maximized. Thus, equating total welfare (efficiency) with firms' value maximization neglects the consumers. In fact, such an equation probably means that one should create either national monopolies or even an huge European one. Because of the well understood and documented dissipation of rents in oligopoly, a potential monopolist may be willing to pay much more for a (monopoly) license than several oligopolists together. Most observers would rightly regard a recommendation to create a monopoly as ridiculous, since it is obvious to them that the impact on consumer welfare will be disastrous. But, the same observers seem to forget their Economics 101 when choosing between designs that yield the one or the other oligopolistic market structures: maximization of total welfare always means that, besides firms' valuations, the regulator must be concerned about the effects on consumers. Consumers' interest should have in fact a very high priority since this group does not participate at auctions, and therefore information about their "willingness to pay" is not revealed nor processed during the bidding process (nor during beauty contests that purport to care for consumers, but, in reality, tend to be determined by political interests, nationalistic preferences, lobbying, explicit or implicit bribes, etc...). Hence the only chance to incorporate consideration of consumers' welfare is at the auction design stage. Unfortunately, at this stage the regulators operate in the dark since information about consumer welfare in various future scenarios cannot be easily measured and anticipated.

One way (and probably the most effective one) to take into account consumer welfare is to encourage market entry. Although there is a myriad of IO models with a myriad of results, as a rule of thumb it is probably wise to assume that in reasonable ranges concerning the number of firms, both consumers' surplus and overall efficiency increase with increased competition among firms. This means that market entry should be encouraged as long as it is economically viable (obviously, the duplication of fixed costs and other factors specific to network industries imply that new entry cannot be without limit). The most important variable for controlling entry is the number of licenses ${ }^{2}$. For example, many

\footnotetext{
${ }^{2}$ There are other regulatory instruments, such as mandatory roaming, mandatory site-sharing and payment for license fees by installments, that reduce fixed costs and/or financing costs for entrants, and hence encourage entry.
} 
country which opted for beauty contests adhered to a simple formula that made entry inevitable:

$$
\text { Number of } 3 \mathrm{G} \text { Licenses }=\text { Number of GSM Incumbents }+1
$$

Also several countries that organized auctions (most notably the UK, which did not even allow GSM operators to bid on the additional license) adopted the above formula. The question is why should one choose a design where entry is inevitable or very likely? Why is it not enough to choose a fair design that gives all firms equal chances to acquire licenses ? Because entry is encumbered by a basic asymmetry among the firms that already operate a GSM $(2 \mathrm{G})$ network in a given country (incumbents) and those that do not (entrants). This asymmetry (as reflected in the respective fixed costs needed to build a $3 \mathrm{G}$ system, financing costs, customer base, recognition and brand names, marketing know-how, etc...) means that incumbents will tend to have higher "pure" valuations for licenses than new entrants $^{3}$. Besides the higher "pure" valuations mentioned above, incumbents' values will be even higher due to pre-emption motives : since per-firm industry profit in oligopoly decreases in the number of active firms, incumbents will be willing to pay large sums of money (even for a license that may be valueless to them!) simply to avoid entry and cannibalization of their existing profits. If potential entrants understand the above $\operatorname{logic}^{4}$, they will either choose not to participate at the auction, or they will try to form consortia with incumbents. Both types of behavior have been amply observed in many of the UMTS auctions, with adverse effect on competitiveness (and hence ultimately on efficiency) and on revenue.

After a regulatory scheme which encourages entry has been chosen, it is possible to concentrate on an auction format that tries to maximize the value for firms. But, as we will argue in the next section, there are many theoretical factors (including the asymmetry among bidders) which make this task rather difficult. Very roughly put, value maximizing multi-object auctions do not exist, and second-best mechanisms are not known.

\subsection{Value Maximization versus Revenue Maximization}

Maximization of revenue has been a secondary goal in the UMTS license auctions. Often this goal has been regarded as the main one by the media, the public, and even by some academic commentators that tend to compare auction outcomes

\footnotetext{
${ }^{3}$ In some cases, it is possible that entrants have higher valuations than incumbents. For example, a particular country may be the "last piece in the puzzle" for an entrant that operates globally. That firm may be willing to pay more than a small incumbent with only local interests. But such features are transient and hard to predict, and should not form the basis of auction design.

${ }^{4}$ Klemperer (2000) points out that small perceived advantages ("toeholds") can be transformed in large advantages during the auction due to cautious behavior in order to avoid the "winner's curse".
} 
on the basis of the associated revenue. It is no wonder that, as the sequence of European auctions proceeded, several governments got very greedy, only to be thoroughly disappointed at a later stage. Revenue maximization seems a legitimate goal, particularly in the cases where it is believed that this form of taxing firms is more efficient (i.e., less distortionary) than other, more traditional taxation schemes.

A widespread idea is that "Value and revenue maximization go hand in hand". The intuition is as follows: if a large pie is created (by maximizing value for the bidders), it will be possible to extract mor revenue; conversely, a large willingness to pay reflected in high bids and revenue) means that a large value has been created. Based on this belief, it seems possible to use revenue maximization as a handy proxy for the more fickle value maximization. This belief is mostly based on powerful results from one-object auction theory. But nothing could be farther from the truth in auctions (even single-object ones) where the valuations are endogenous due to the external effects caused by market structure considerations, or in multi-object auctions with either exogenous or endogenous valuations: there is no general relation between efficiency and revenue! Not even in a completely standard multi-object model with no externalities whatsoever, no complementarities, no nothing..., is it true that the auction that maximizes revenue is efficient nor vice-versa. In particular, this means that multi-object auctions that maximize revenue will not necessarily put the objects in the hands of those that value them most.

Since this last argument is exceedingly simple, it is worth it mentioning here (see also Jehiel and Moldovanu, 2001b). Consider an auction for two objects $A$ and $B$, and two bidders, 1 and 2 . For both agents, the valuations for the bundle $\{A, B\}$ are given by the sum of the valuations for the individual objects, and assume these to be as follows:

$$
\begin{aligned}
& v_{1}^{A}=10 ; v_{1}^{B}=7 \\
& v_{2}^{A}=8 ; v_{2}^{B}=12
\end{aligned}
$$

The value maximizing auction (which puts the objects in the hand of those who value them most) is simply given by two separate second-price auctions, one for each object. Then object $A$ goes to bidder 1 for a price of 8 , while object $B$ goes to bidder 2 for a price of 7 . Total revenue is 15 . But, consider now a single second-price auction for the entire bundle $\{A, B\}$. Then the bundle will be acquired by bidder $B$, for a price of 17 ! Hence, revenue is higher in the bundle auction, but object $A$ is miss-allocated. Such a phenomenon occurs as soon as bidders do not have single unit demand (e.g., in the German setting where blocks of capacity were auctioned instead of licenses) 


\section{The Theory of Value and Revenue Maximization in Auctions}

Given the above widespread misconceptions, it is important to get an idea about the main auction-theoretical results concerning revenue and value maximization. This is surely not the place for an exhaustive survey, and we apologize to all authors whose important results will not be included below. In particular, we will consider only risk-neutral bidders.

Besides the obvious dependence on auction rules, the most important determinants of theoretical auction performance are related to the economics of demand in the underlying situation. Here are several crucial properties:

1. Bidder Symmetry. We say that bidders are (ex-ante) symmetric if their utility functions have the same functional form.

2. Informational Externalities. We say that the economic situation displays informational externalities if the valuation of one agent depends on information available to another agent, i.e., the valuations contain common components (For example consider two firms that bid for an oil field. If one firm has an adjacent field, and has already conducted a geological survey, the information contained in the survey affects the valuations of both firms)

3. Allocative Externalities. We say that the economic situation displays allocative externalities if the valuation of one bidder depends on the entire allocation of physical goods to herself and other bidders. (For example, in a license auction, the valuation of a monopolist incumbent may depend on whether one or two licenses are auctioned. In the latter case entry is possible, with an adverse effect on the monopolist's future profits.)

4. Homogeneity/Heterogeneity of Goods. In an auction where several objects are sold, we say that the objects are homogenous if they are indistinguishable from each other. Otherwise, objects are heterogenous.

5. Complementarities among Goods. In an auction where several objects are sold, we say that the objects are (positive or negative) complements if the value attached to a bundle is not equal to the sum of the values attached to the individual objects in the bundle.

6. Unit Demand/Multi-unit Demand. We say that bidders have unit demand if, in a multi-object auction, their demand is satiated after they acquire one object. Otherwise, we say that bidders have multi-unit demand.

Generally speaking, the presence of asymmetries, heterogeneity, externalities and complementarities all hinder value-maximization in auctions. 


\subsection{Results for Single-Object Auctions}

1. Classical auction formats (such as sealed-bid auctions, ascending, descending, all-pay, etc...) are both value-maximizing and revenue maximizing (when augmented by simple instruments such as reserve prices or entry fees) if bidders are symmetric, and if there are no allocative or informational externalities (Vickrey, 1961, Myerson, 1981, etc...).

2. The so called Clarke-Groves-Vickrey (CGV) mechanisms are value-maximizing even if bidders are asymmetric and even if there are allocative externalities (Clarke, 1971, Groves, 1973, Vickrey, 1961).

3. The English ascending auction is value-maximizing even if there are asymmetric bidders and informational externalities, as long as there are no allocative externalities (Maskin, 1992, Krishna, 2000, Izmalkov, 2001).

4. Modified CGV mechanisms are value-maximizing even if there are asymmetric bidders, and even if informational and allocative externalities are present (Jehiel and Moldovanu, 2001a)

5. In general, allocative or informational externalities drive a wedge between value-maximization and revenue (Jehiel and Moldovanu, 1996, 1999)

\subsection{Multi-Object Auctions}

1. CGV mechanisms are value-maximizing as long as there are no informational externalities (Clarke, 1971, Groves, 1973, Vickrey, 1961). In that case, the CGV mechanisms are revenue maximizing among value maximizing mechanisms (Krishna and Perry, 1998). With additional assumptions (e.g., either unit demand, or non-complementarities, or homogenous goods) it is possible to implement the value maximizing outcome by an ascending, multi-object auction (Ausubel, 1997, Ausubel and Milgrom, 2001, Demange, Gale, and Sotomayor, 1986, Gul and Stacchetti, 1999, Bikhchandani and Ostroy, 2000a/b, Milgrom, 2000).

2. Modified CGV mechanisms are value-maximizing even if bidders are asymmetric and there are informational externalities as long as there are no allocative externalities and no complementarities. (Ausubel, 1997, Cremer and McLean, 1988, Dasgupta and Maskin, 2000, Jehiel and Moldovanu, 2001). With additional assumptions (e.g., homogenous goods) bidding mechanism can be constructed that attain the value-maximizing outcome (Perry and Reny, 1999).

3. Assume either: 1) Bidders are asymmetric, objects are heterogenous, there are informational externalities and complementarities; or 2) Bidders are asymmetric and there are both informational and allocative externalities. 
Then value-maximizing auctions do not exist (Jehiel and Moldovanu, 2001a). Moreover, constrained (i.e., second-best) value maximizing auctions are not yet known.

4. In general, the multi-object revenue maximizing auction is not known. The maximization problem (which resembles the one for finding constrained value maximizing mechanisms - see point 3 above) involves a complex integrability constraint (or, equivalently, a constraint which is represented by a complex partial differential equation) (Jehiel and Moldovanu and Stacchetti, 1999).

\section{The German and Austrian Auctions}

\subsection{Design and Outcomes}

The rather complex design (which was shared by both countries) involved two consecutive auctions. ${ }^{5}$ The first auction allocated licenses together with so called "duplex" or "paired" spectrum frequencies. The second auction allocated paired spectrum that has not been sold at the first auction, together with additional "unpaired" spectrum. Both auctions were of the "simultaneous multiple-round ascending" type. We focus below on the first, main auction.

Bidders did not directly submit bids for licenses. Instead, the auctioned objects were 12 abstract blocks of paired spectrum.

A bidder obtained a license only if he acquired at least two blocks, but a bidder was allowed to acquire (at most) three blocks. The number of licensed firms was therefore variable (between 0 and 6 ). If all blocks get sold, then there were bound to be at least 4 licenses (this equaled the number of GSM incumbents in both Germany and Austria).

Each block had a reserve price of DM 100 Million in Germany and Euro 50 Million in Austria. At each round a bidder had to bid on at least two blocks. Strangely enough, although the blocks were abstract and identical, bids carried name tags ${ }^{6}$ ! Bidding on only two blocks at round $t$ precluded bidding on three blocks at all rounds $t^{\prime}>t$.

A block could have remained unsold either because there were no bids for that block above the reserve price, or because the bidder who submitted the last highest bid on that particular block ultimately failed to acquire two blocks , in which case he was not required to make a payment.

In Germany there were 7 bidders (including 4 GSM incumbents), after 6 other qualified bidders ultimately withdrew from the auction. The auction lasted for 3

\footnotetext{
${ }^{5}$ For details on the design, see the official document by the RegTP (2000).

${ }^{6}$ For example, the Italian design, which auctioned 5 identical licenses required from bidders just a bid (without specification to which license it applied).
} 
weeks and 173 rounds of bidding, and resulted in 6 licenses being awarded (4 of them to the existing GSM operators). The licensed firms were the 4 incumbents and two new entrants (one of them already operating as service provider). Each licensed firm acquired 2 blocks of paired spectrum, paying approximately Euro 8.4 Bn (or Euro 4.2 Bn per block). The most interesting thing occurred after one of the potential entrants, Debitel, left the auction after 125 rounds and after the price level reached Euro 2.5 Bn per block. Since 6 firms were left bidding for a maximum of 6 licenses, the auction could have stopped immediately. Instead, the remaining firms (and in particular the two large incumbents) continued bidding in order to acquire more capacity. But no other firm was willing to quit, and bidding stopped in round 173. Compared to round 125, there was no change in the physical allocation, but firms where, collectively, Euro 20 Bn poorer! ${ }^{7}$

In Austria there were exactly 6 bidders (4 of them GSM incumbents) for a maximum of 6 licenses. Hence, in principle, the license auction could have ended immediately, at the reserve price (Euro 100 mil. per license). Nevertheless, the auction continued for another 16 rounds, before stopping with...6 licensed firms (4 of them to the existing GSM operators), each paying on average about Euro 118 mil. per license. Hence, about Euro 108 mil. have been again spent for nothing.

\subsection{Benefits and Disadvantages of the German and Austrian Design}

A main perceived advantage of the German auction was its flexibility. It has been argued that ex-ante carving of spectrum in fixed chunks of capacity cannot be efficient, since the regulator is less informed about the precise operational needs of the involved firms. On the same vein, since the regulator does not really know how many firms are efficient, why not let firms themselves determine the number of licenses in a competitive bidding process? These arguments are not entirely correct, since thgey confuse value maximization (for the involved firms) with efficiency, thus neglecting consumers. From the point of view of value maximization, a design which allows for a variable number of small and large licenses seems more desirable than those designs where the number of licenses and their capacity where fixed ex-ante. While this argument is correct, its implementation in the German and Austrian design mixed flexibility in that dimension with flexibility concerning the number of firms. Since the overall industry profits fall in the number of firms, while consumer surplus probably increases, it is obvious that letting the firms themselves decide how many of them will be able to operate in the market is very problematic form the point of view of consumers, and hence for overall efficiency.

Consider a hypothetical story where the regulator proposes the following regulatory scheme to existing firms in the market: each firm has to pay a hefty fee to

\footnotetext{
${ }^{7}$ The outcome was so unfortunate that Deutsche Telekom became apologetic after the auction. See Financial Times (2000).
} 
the state; depending on the paid fees, the regulator allows more or less (possibly none) new firms in the market, with higher fees meaning less firms. Sounds ridiculous ? But this was, roughly speaking, how the German and Austrian designs operated, and this feature has been highly praised by some observers.

Despite the above crucial caveat, it is instructive to judge the design in terms of its ability to achieve value and/or revenue maximization in light of the properties listed in the previous Section:

1. By introducing bidding on 1,2 , or 3 blocks rather than directly on licenses, the auction artificially created a situation with multi-unit demand, and therefore offered scope for demand reduction gaming effects. While such effects usually lead to inefficiencies, here it may, in fact, have had some positive effect since they can partly combat the opposite demand increasing effect due to allocative externalities (see point 3 below)

2. It is obvious that complementarities existed among blocks. The first block was worth nothing, the second a lot, and the third had a positive value.

3. By completely endogenising the firms' valuations (since number of firms and capacities were endogenous) the auction focused most of the strategic behavior on the allocative externalities, and created an artificial demandincreasing effect. For example, the intrinsic value of a third block of capacity was greatly augmented in feasible scenarios where acquiring such a block leads to less firms in the market. It is impossible to say with certainty whether demand reduction was stronger than artificial demand increase or vice versa since the strengths of these effects depends on the level of prices. Obviously, demand increase played the major role following Debitel's quitting, and demand reduction finally took place when prices reached very high levels.

4. In auctions with allocative externalities, a revenue-maximizing seller can extract revenue by "threats" to sell exactly to those agents that create negative externalities on others (Jehiel, Moldovanu, and Stacchetti 1996, 1999). I am happy to say that this argument was very well understood by the auction designers (see the demand increase effect at the previous point). By allowing 4 to 6 firms, such a threat to sell to newcomers was in effect operative, and, in principle, avoidable for a high enough price. Some commentators argued that the German design was therefore much better geared towards revenue maximization. If endogenous entry decisions are neglected, this argument is correct.

5. Last, but not least, the multi-unit-demand and complementarity features created a massive exposure and regret problem for the involved firms (since exclusive combinatorial bids on entire packages were not allowed). It is 
therefore no wonder that Euro 20 billion were spend on nothing in the German auction, and that firms quickly learned to avoid this catastrophe (by relatively fast demand reduction) in the Austrian auction. Generally speaking, auctions that create exposure and regret phenomena are not attractive for bidders which may rationally decide to avoid bidding altogether.

In the next section we want to analytically focus on this exposure problem, since it was somewhat neglected in the debate so far.

\section{The Exposure Problem in the German Design}

\subsection{Flexibility vs. Risk}

The presence of exposure risks in multi-unit license auctions has been identified before, e.g., by Cramton (1997) in the context of the FCC spectrum auctions ${ }^{8}$. Cramton uses a simple example in order to show that, with increasing marginal valuations for several objects, bidders risk getting stuck with less of what they attempted to acquire. While the basic idea of the subsequent analysis is in the same spirit, we do not presuppose increasing marginal valuations. Indeed, our discussion shows that the exposure problem in the German design was a consequence of the fact that the flexible German design has been combined with a de-facto uniform-price auction. Specifically, when a dominant incumbent tries to push the weakest entrant out of the market, he may be unsuccessful and suffer from regret. The attempt to create a more concentrated market structure may drive prices up for all acquired frequency blocks without changing the allocation.

This is the basic idea underlying Ewerhart and Moldovanu's (2001) analysis. The model used in this paper combines elements of the complete information setting of Jehiel and Moldovanu (2000b) with existing models of uniform-price auctions, as analyzed by Noussair (1995) and Engelbrecht-Wiggans and Kahn (1998).

\subsection{A Stylized Model}

The model developed below will abstract from a number of facts that were present in the actual situation. Firstly, we will focus on the first stage of the German design. The bidders' valuations in the subsequent analysis should therefore be interpreted as valuations that the firms attribute to specific outcomes of the first stage. We will discuss later why the second stage does not affect our arguments. We will also abstract from the fact that the German license auction must be properly considered as a part of a more global process, in which international telecom firms have fought about the position in the European market. E.g., it has been suggested by van Damme (2001) that the high prices in Germany resulted from a

\footnotetext{
${ }^{8}$ See also and Ausubel and Cramton (1998).
} 
struggle mainly between KPN, represented by E-Plus, and Telefonica, represented by Group 3G. Moreover, while financial externalities and credit constraints might have played a significant role, we will also abstract from these complications.

The formal analysis starts with a setting in which 12 frequency blocks are sold to $i=1, \ldots, n$ bidders. Bidder $i$ has valuations $v_{m}^{i}(k)$ for a $m$-block license in a $k$-player market, where $m \in\{2,3\}$ and $k \in\{4,5,6\} .{ }^{9}$ The auction is open and ascending and most easily viewed as a clock auction. Each bidder may bid for two or three blocks, and an activity rule specifies that demand may not increase during the auction.

The final price is the lowest price $p^{*}$ at which aggregate demand drops to 12 or even lower. If aggregate demand drops to precisely 12, then the corresponding highest bids are satisfied. Otherwise a randomizing tie-breaking rule is applied, whose specification is of minor importance in the sequel. Essentially, each bidder submits a bid $b^{i}=\left(b_{3}^{i}, b_{2}^{i}\right)$, where $b_{3}^{i}$ is the price level at which $i$ 's demand is reduced from three to two units, and $b_{2}^{i}$ is the price level where bidder $i$ drops out completely.

While the above specification is of the "sealed bid type", our informational assumptions mean that bidders do not learn new information during the auction.

\subsection{Assumptions}

Ewerhart and Moldovanu (2001) make a number of assumptions that focus the analysis on the case that had been observed. Firstly, there are only $n=6$ bidders (i.e., the analysis focusses on the main stage of interest which starts when the number of bidders precisely equals the maximal number of licenses and the auction could have been immediately stopped). Bidders are ordered according to their valuations, with bidder 1 , the dominant incumbent, having the highest valuations. Thus, we require that $v_{m}^{i}(k)$ is decreasing in $i$. Moreover, we assume that valuations $v_{m}^{i}(k)$ are increasing in the number of blocks $m$, and decreasing in the number of players in the market $k$.

The weakest bidder's (i.e., the weakest entrant's) valuation for a small twoblock license is denoted by $v:=v_{2}^{6}(6)$. We assume that $v$ is uncertain ex-ante, and is distributed on an interval $[\underline{v}, \bar{v}]$ such that

$$
\frac{\underline{\bar{v}}}{2}<\frac{v_{3}^{1}(5)}{3}<\frac{\bar{v}}{2}
$$

This assumption generates an uncertainty about whether the per-block valuation of the dominant incumbent for a large license is higher or lower than the per-block valuation of the weakest entrant for a small license.

Finally, it is assumed that the value of the third block is not too large for

\footnotetext{
${ }^{9}$ In the actual setting, the second stage opened the theoretical possibility to obtain even 4 blocks. As mentioned before, for simplicity, we will abstract here from the second stage.
} 
bidders 2 to 6 , i.e., that

$$
\frac{v_{3}^{2}(4)}{3}<\frac{\bar{v}}{2}
$$

Figure 1 illustrates the per-block valuations in the stylized model of the UMTS auction. On the left-hand side, one sees the per-block valuation of the weakest bidder 6 for a large license in a concentrated market, i.e., in a market with 5 players. Going to the right, we have the corresponding valuations for bidders 5 to 1 . Next, one has the uncertain valuation for the weakest entrant $v_{2}^{6}(6) / 2$, that may vary between $\underline{v} / 2$ and $\bar{v} / 2$. Still further to the right we depicted the per-unit valuations of the remaining bidders 5 to 1 for a small license in a less concentrated market.

\subsection{Equilibrium}

Ewerhart and Moldovanu (2001) show that the following bidding behavior constitutes an equilibrium in the stylized UMTS auction: With the exception of the strongest incumbent bid, each bidder $i$ bids his true per-block valuations in the sense that they bid for three units up to $v_{3}^{i}(5) / 3$, and for two units up to $v_{2}^{i}(6) / 2$. Bidder 1 , in contrast, bids only up to some price level $\beta^{*}$ for three units. Equilibrium behavior is illustrated in Figure 1. When prices increase, all six bidders first reduce their demand from three to two, one by one, and starting with the weakest bidders. It can be shown that, depending on the parameters of the model, each of the two alternative equilibria may occur:

1. ("accommodate") In this case $\beta^{*}=v_{3}^{2}(5) / 3$, so that bidder 1 reduces his demand for the third unit in accordance with the second strongest bidder 2 , and the auction ends at a price $p_{0}=v_{3}^{2}(5) / 3$ with a six-player market.

2. ("fight") In this case bidder 1 keeps up demand for three units up to a level of $\beta^{*} \in\left[\underline{v} / 2, v_{3}^{1}(5) / 3\right]$ and tries to push the weakest entrant out of the market. In that equilibrium two things may happen. If $\beta^{*}>v / 2$, the dominant incumbent wins the battle, and the auction ends with a price of $v / 2$, allocating a large license to the dominant incumbent, and small licenses to bidders 2 to 5 . Otherwise, the entrant wins the battle, and a six-player market results with a final per-block price of $\beta^{*}$. The optimal bid $\beta^{*}$ for the incumbent maximizes the expected profit function

$$
U_{1}(\beta)=\int_{\underline{v}}^{2 \beta}\left\{v_{3}^{1}(5)-\frac{3 v}{2}\right\} d F(v)+\int_{2 \beta}^{\bar{v}}\left\{v_{2}^{1}(6)-2 \beta\right\} d F(v),
$$

where $F(v)$ is the cumulative distribution function corresponding to the distribution of $v$. Hence, $\beta^{*}$ is implicitly given by

$$
\beta^{*}+\frac{1-F\left(2 \beta^{*}\right)}{F^{\prime}\left(2 \beta^{*}\right)}=v_{3}^{1}(5)-v_{2}^{1}(6) .
$$


Formula 4.4 shows that the dominant incumbent lowers his bid as a consequence of the exposure.

Both equilibria are stable with respect to the introduction of a second stage, under some additional assumptions. Specifically, when we assume that the marginal valuation of a fourth block is lower than the marginal valuation of a third block, then the second stage will always end with giving any remaining block to bidder 2. When the additional value that bidder 2 has from obtaining a third block in the second stage is taken into account in the first stage, this will increase the valuation of bidder 2 for a small license in a concentrated market with five players, but leave the valuations of both bidders 1 and 2 for a large license in a concentrated market unaffected. But then it is immediate from Figure 1 that the second stage does not affect equilibrium behavior. ${ }^{10}$

\subsection{Regret}

The second equilibrium illustrates the exposure problem. Specifically, when the incumbent tries to push the entrant out of the market, but is ultimately unsuccessful, he increases the prices for the two blocks he could acquire for sure, so that regret may occur. Technically, this means that the outcome does not constitute an ex-post equilibrium ${ }^{11}$. The regret can be made explicit by considering the difference in expected utility between fighting and accommodating:

$$
\begin{aligned}
\Delta U_{1}= & \operatorname{pr}\left(\frac{v}{2}<\beta\right)\left\{v_{3}^{1}(5)-v_{2}^{1}(6)-p_{0}-3 \Delta^{w}\right\} \\
+ & \operatorname{pr}\left(\frac{v}{2} \geq \beta\right)\left\{-2 \Delta^{l}\right\},
\end{aligned}
$$

where

$$
\begin{aligned}
\Delta^{w} & =E\left[\frac{v}{2} \mid \frac{v}{2}<\beta\right]-p_{0} \\
\Delta^{l} & =\beta-p_{0}
\end{aligned}
$$

is the expected increment in the price per block in cases where the incumbent wins and loses the battle, respectively.

The above expression captures the regret effect as follows: In case that the incumbent wins, he earns an incremental utility that corresponds to the difference between his valuation of a large license in a concentrated market and his valuation of a small license in a less concentrated market. But he also has to pay the accommodating price $p_{0}$ for the additional block, and, for each of the three blocks,

\footnotetext{
${ }^{10}$ In contrast, the second stage is strategically relevant in Wolfstetter (2001), who assumes that two dominant incumbents have the potential to push out an incumbent.

${ }^{11}$ In an ex-post equilibrium, agents do not wish to change their actions even after learning the private information held by their competitors. This concept is stronger that Bayes-Nash equlibrium, but weaker than dominant strategy equilibrium.
} 
the expected price increment conditional on his winning the battle. In the other case, i.e., when the incumbent loses the battle, he realizes a loss on each of the two remaining frequency blocks, which corresponds to the expected price increment conditional on his losing the battle. This second expression captures the regret outcome because $\Delta^{l}$ is the per-block price increment that is spuriously paid when the battle is lost, and the outcome is the same as the one occurring at the lower price level.

\section{Conclusion}

This survey has reviewed a number of insights about value and revenue maximization objectives in multi-unit auctions. In the light of these insights, we have discussed several advantages and potential problems of the German UMTS auction. That design allowed a flexible allocation of capacity which is an advantage vis-à-vis less flexible designs. But, under incomplete information, and in the presence of externalities stemming from market structure considerations, this flexibility has caused a significant exposure for bidders, with the potential of inefficient non-participation and of shareholder value destruction. Because the flexible design allows incumbents to fight entrants, the prices paid in the flexible design can be strictly higher than those resulting from a less flexible design yielding the same outcome. Moreover, the flexible design included the risk of a concentrated market structure, with adverse effects on consumers. For this reason, and because the huge exposure problem affected the financial stability of the telecommunications industry, we question the efficiency gains obtained with a flexible design.

\section{References}

Ausubel, L. (1997): "A Efficient Ascendig-Bid Auction For Multiple Objects," discussion paper, University Maryland, 1997.

Ausubel, L. M. and P. Cramton (1998): "Demand Reduction and Inefficiency in Multi-Unit Auctions," working paper, University of Maryland.

Ausubel, L. M., and P. Milgrom (2001): "Ascending Auctions with Package Bid," mimeo, University of Maryland and Stanford University.

Bikhchandani and Ostroy (2000a): "The Package Assignment Model," mimeo, UCLA.

Bikhchandani and Ostroy (2000b): “Ascending Price Vickrey Auctions, ” mimeo, UCLA.

Börgers, T., and Dustmann, J. (2001): "Strange Bids, Bidding Behavior in the United Kingdom's Third Generation Spectrum Auction," Discussion Paper, University College, London. 
Caillaud, B. and P. Jehiel (1998): "Collusion in auctions with externalities," Rand Journal of Economics 29, 680-702.

Clark, E. (1971): "Multipart Pricing of Goods", Public Choice 8, 19-33.

Cramton, P. (1997): "The FCC Spectrum Auctions: An Early Assessment," Journal of Economics \& Management Strategy 6(3), 431-495.

Cremer, J., and R. McLean (1988): "Full Extraction of Surplus in Bayesian and Dominant Strategy Auctions", Econometrica 56(6), 1247-1257.

Dasgupta, P., and E. Maskin ( 2000): “Efficient Auctions", Quarterly Journal of Economics 115(2), 341-389.

Demange, G., D. Gale, and M. Sotomayor (1986), "Multi-item auctions," Journal of Political Economy, 94, 863-72.

Engelbrecht-Wiggans, R., and C. M. Kahn (1998): "Multi-Unit Auctions with Uniform Prices," Economic Theory 12, 227-258.

Ewerhart, C., and B. Moldovanu (2001): "A Stylized Model of the German UMTS Auction," discussion paper, University of Mannheim.

Deutsche Bank (2000): "UMTS, The Third Generation Game," Deutsche Bank Equity Research.

Engelbrecht-Wiggans, R., and C. M. Kahn (1998): "Multi-Unit Auctions with Uniform Prices," Economic Theory 12, 227-258.

Financial Times (2000): "German 3G auction raises Euro 51bn," August 8th, 2000.

Gilbert, R., and D. Newberry (1982): "Preemptive Patenting and the Persistence of Monopoly, American Economic Review 72, 514-526.

Grimm, V., Riedel, F., and E. Wolfstetter (2001): "The Third Generation (UMTS) Spectrum Auction in Germany," working paper, Humboldt University, Berlin.

Groves, T. (1973): "Incentives in Teams," Econometrica 41, 617-631.

Gul, F., and E. Stacchetti (1999), "Walrasian Equilibrium with Gross Substitutes," Journal of Economic Theory 87, 9-124.

Izmalkov, S. (2001), "English Auctions with Reentry," discussion paper, Penn State University

Jehiel, P., and Moldovanu, B. (1996): "Strategic Non-Participation," RAND Journal of Economics 27(1), 84-98

Jehiel, P., and B. Moldovanu (2000a): "License Auctions and Market Structure," discussion paper, Mannheim University and CEPR.

Jehiel, P., and Moldovanu, B. (2000b): "The European UMTS License Auctions," discussison paper, Mannheim University and CEPR 
Jehiel, P., and B. Moldovanu (2000c): "Auctions with Downstream Interaction among Buyers," RAND Journal of Economics 31(4), 768-791.

Jehiel, P., and Moldovanu, B. (2001a): "Efficient Design with Interdependent Valuations," Econometrica 69 (5), 1237-1259

Jehiel, P., and Moldovanu, B. (2001b): "A Note on Efficiency and Revenue Maximization in Multi-Object Auctions," Economic Bulletin 3(2), 2-5

Jehiel, P., B. Moldovanu, and E. Stacchetti (1996): " How (not) to Sell Nuclear Weapons," American Economic Review 86, 814-829.

Jehiel, P., B. Moldovanu and E. Stacchetti (1999): "Multidimensional Mechanism Design for Auctions with Externalities," Journal of Economic Theory 85, 258-293.

Klemperer, P. (1999): "Auction Theory: A Guide to the Literature", Journal of Economic Surveys 13, 227-286.

Klemperer, P. (2000): "What Really Matters in Auction Design," mimeo, Oxford University.

Klemperer, Paul, ed. (2000): The economic theory of auctions. 2 vols.. [Book] Elgar Reference Collection. International Library of Critical Writings in Economics, vol. 113. Cheltenham, U.K. and Northampton, Mass.: Elgar; distributed by American International Distribution Corporation, Williston, Vt. p x, 679; x, 692 .

Klemperer, P. (2001): "Case Study on European 3G (UMTS) Mobile-Phone Auctions," working paper, University of Oxford.

Krishna, V. (2000): "Asymmetric English Auctions.", discussion paper, Penn State University

Krishna, V., and M. Perry (1998), "Efficient Mechanism Design," mimeo, Pennsylvania State University.

Maskin, E. (1992): “Auctions and Privatizations", Privatization, H. Siebert (ed), Kiel 1992.

McAfee, R.P., and J. McMillan (1996): "Analyzing the Airwaves Auction," Journal of Economic Perspectives 10, 159-175.

McMillan, J. (1994): "Selling Spectrum Rights," Journal of Economic Perspectives $8,145-162$.

Milgrom , P. (2000): "Putting Auction Theory to Work", Journal of Political Economy, 108, 245-272.

Myerson, R. (1981): "Optimal Auction Design", Mathematics of Operations Research $6,58-73$.

Noussair, C. (1995): "Equilibria in a Multi-Object Uniform Price Sealed Bid Auction with Multi-Unit Demands," Economic Theory 5, 337-351. 
Perry, M., and P. Reny (1999): "An Ex-Post Efficient Multi-Unit Auction for Agents with Interdependent Valuations", discussion paper, University of Chicago.

REG-TP (2000): "Entscheidung der Präsidentenkammer vom 18.02.2000 über die Regeln für die Durchführung des Versteigerungsverfahrens zur Vergabe von Lizenzen für UMTS/IMT-2000; Mobilkommunikation der dritten Generation Aktenzeichen BK-1b-98/005-2," official declaratory document.

UBS Warburg (2000): "3G hysteria! Not everyone's idea of fun and games", mimeo, UBS Global equity Research.

van Damme, E. (2000): "The Dutch UMTS Auction in Retrospect," cpb Report $2001 / 2$.

Vickrey, W. (1961): "Counterspeculation, Auctions, and Competitive Sealed Tenders ", Journal of Finance 16, 8-37.

WestLB Panmure (2000): "UMTS. The countdown has begun", mimeo, WestLB Panmure, Pan European Equity. 


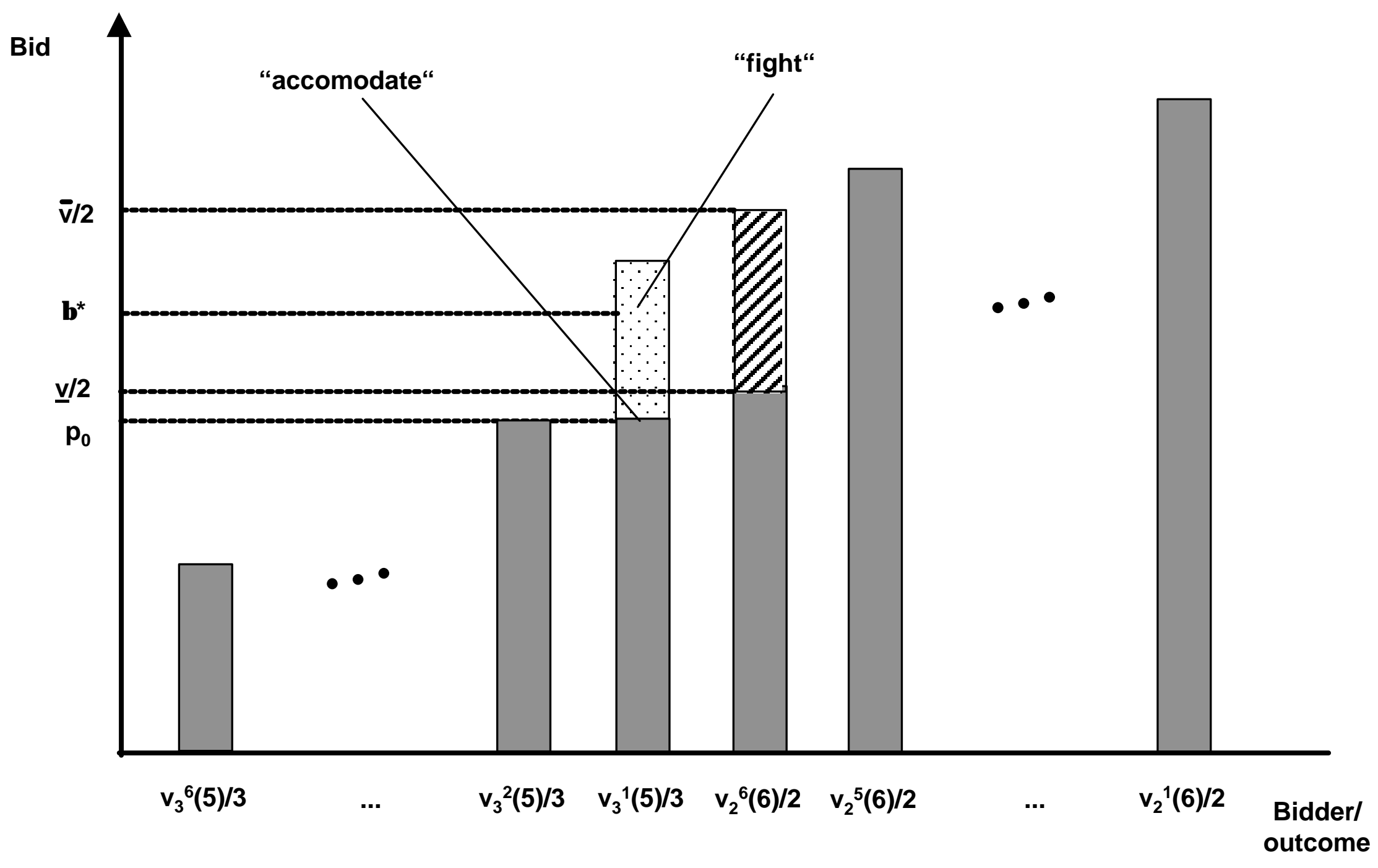

Figure 1 : Equilibrium bids in the stylized UMTS auction 


\begin{tabular}{|c|c|c|}
\hline Nr. & Author & Title \\
\hline 02-08 & $\begin{array}{l}\text { Benny Moldovanu } \\
\text { Moritz Meyer-ter-Vehn }\end{array}$ & $\begin{array}{l}\text { Ex-post Implementation with Interdependent } \\
\text { Valuations }\end{array}$ \\
\hline 02-07 & $\begin{array}{l}\text { Benny Moldovanu } \\
\text { Christian Ewerhart }\end{array}$ & A Stylized Model of the German UMTS Auction \\
\hline 02-06 & $\begin{array}{l}\text { Benny Moldovanu } \\
\text { Aner Sela }\end{array}$ & Contest Architecture \\
\hline $02-05$ & $\begin{array}{l}\text { Benny Moldovanu } \\
\text { Christian Ewerhart }\end{array}$ & $\begin{array}{l}\text { The German UMTS Design: Insights From } \\
\text { Multi-Object Auction Theory }\end{array}$ \\
\hline $02-04$ & Alex Possajennikov & $\begin{array}{l}\text { Cooperative Prisoners and Aggressive Chickens: } \\
\text { Evolution of Strategies and Preferences in } 2 \times 2 \\
\text { Games }\end{array}$ \\
\hline $02-03$ & Alex Possajennikov & $\begin{array}{l}\text { Two-Speed Evolution of Strategies and Preferences } \\
\text { in Symmetric Games }\end{array}$ \\
\hline 02-02 & $\begin{array}{l}\text { Markus Ruder } \\
\text { Herbert Bless }\end{array}$ & $\begin{array}{l}\text { Mood and the reliance on the ease of retrieval } \\
\text { heuristic }\end{array}$ \\
\hline $01-52$ & $\begin{array}{l}\text { Martin Hellwig } \\
\text { Klaus M. Schmidt }\end{array}$ & $\begin{array}{l}\text { Discrete-Time Approximations of the } \\
\text { Holmström-Milgrom Brownian-Motion Model of } \\
\text { Intertemporal Incentive Provision }\end{array}$ \\
\hline $01-51$ & Martin Hellwig & $\begin{array}{l}\text { The Role of Boundary Solutions in Principal-Agent } \\
\text { Problems with Effort Costs Depending on Mean } \\
\text { Returns }\end{array}$ \\
\hline $01-50$ & Siegfried K. Berninghaus & $\begin{array}{l}\text { Evolution of conventions - some theoretical and } \\
\text { experimental aspects }\end{array}$ \\
\hline $01-49$ & Dezsö Szalay & Procurement with an Endogenous Type Distribution \\
\hline $01-48$ & $\begin{array}{l}\text { Martin Weber } \\
\text { Heiko Zuchel }\end{array}$ & $\begin{array}{l}\text { How Do Prior Outcomes Affect Risky Choice? } \\
\text { Further Evidence on the House-Money Effect and } \\
\text { Escalation of Commitment }\end{array}$ \\
\hline $01-47$ & $\begin{array}{l}\text { Nikolaus Beck } \\
\text { Alfred Kieser }\end{array}$ & $\begin{array}{l}\text { The Complexity of Rule Systems, Experience, and } \\
\text { Organizational Learning }\end{array}$ \\
\hline
\end{tabular}

